\title{
Thermodynamic Study of the Solubility of Acetaminophen in Propylene Glycol + Water Cosolvent Mixtures
}

\author{
Jackson A. Jiménez and Fleming Martínez* \\ Departamento de Farmacia, Universidad Nacional de Colombia, A.A. 14490, Bogotá D.C., Colombia
}

\begin{abstract}
Baseado nas equações de van't Hoff e Gibbs, as funções termodinâmicas energia de Gibbs, entalpia e entropia de solução, mistura e solvatação de acetaminofen em misturas dos solventes propileno glicol + água $(\mathrm{PG}+\mathrm{W})$, foram avaliadas por medidas de solubilidade em diversas temperaturas. A solubilidade foi maior para $100 \%$ de PG em todas as temperaturas estudadas. A solvatação dessa droga nas misturas aumenta com o aumento da proporção de PG, atingindo um máximo em $70 \%$ de PG. De $0 \%$ até $20 \%$ de PG e de solução $70 \%$ até $100 \%$ de PG, foi encontrado um domínio da entropia sobre o processo, enquanto de água pura até $10 \%$ de PG e de $20 \%$ até $70 \%$ de PG, foi encontrado domínio da entropia. Estes fatos são explicados em termos de perda da estrutura da água, e uma diminuição na energia requerida para formação da cavidade no solvente, para misturas de $30 \%$ até $70 \%$ de PG.
\end{abstract}

Based on van't Hoff and Gibbs equations the thermodynamic functions Gibbs energy, enthalpy, and entropy of solution, mixing and solvation of acetaminophen in propylene glycol + water $(\mathrm{PG}+\mathrm{W})$ cosolvent mixtures, were evaluated from solubility data determined at several temperatures. The solubility was greater at $100 \%$ of PG at all temperatures studied. The solvation of this drug in the mixtures increases as the PG proportion is also increased founding a maximum at $70 \%$ of PG. From $10 \%$ up to $20 \%$ of PG and from $70 \%$ up to $100 \%$ of PG, entropy driving was found, while from pure water up to $10 \%$ of PG and from $20 \%$ up to $70 \%$ of PG, enthalpy driving was found. These facts can be explained in terms of water-structure loss, and a diminishing in the energy required for cavity formation in the solvent, for mixtures from $30 \%$ up to $70 \%$ of PG.

Keywords: acetaminophen, solubility, solution thermodynamics, activity coefficients

\section{Introduction}

Acetaminophen is an analgesic and antipyretic drug widely used in modern therapeutics. This drug is specially indicated in the treatment of several minor diseases presented by pediatric patients. ${ }^{1}$ In the Colombian market, it is commercially available as tablets, syrups and concentrates, but it is not available as parenteral products. The later ones have been recently asked for by physicians and by other care practitioners. Injectable homogeneous liquid formulations supply relatively high doses of drug in small volumes. For this reason, some physicochemical properties such as the solubility and the occupied volumes by the drugs and other components in the solution are very important because they facilitate the design process of pharmaceutical dosage forms. ${ }^{2}$

* e-mail: fmartinezr@unal.edu.co
The solubility behavior of drugs in cosolvent mixtures takes great importance because cosolvent blends are frequently used in purification methods, preformulation studies, and pharmaceutical dosage forms design, among other applications. ${ }^{3}$ Nowadays several methods to calculate the solubility are available. However, these methods do not explain totally the mechanism of cosolvent action in mixtures. On the other hand, almost all of these methods in general do not consider the effect of temperature. For these reasons, it is important to determine, systematically, the solubility of drugs, in order to obtain complete information about physicochemical data of pharmaceutical systems. This information facilitates widely the labor of pharmacists associated to development and research of new products in pharmaceutical industry. ${ }^{4}$ Temperature-solubility dependence allows to carry out the respective thermodynamic analysis, which, at the same time, permits explain the molecular mechanisms, involved in the solution processes. $^{5}$ 
The main objective of this study was to evaluate the effect of the cosolvent composition on solubility and solution thermodynamics of acetaminophen in propylene glycol + water cosolvent mixtures. The analysis was based on van't Hoff method, including the respective contributions by mixing and solvation of the drug on the solution processes. Ethanol and propylene glycol are probably the more widely used cosolvents in parenteral medications. This investigation expands the concepts developed for this drug in cosolvent systems by Pérez et $a l .{ }^{2}$ in ethanol + water, propylene glycol + water, and ethanol + propylene glycol mixtures at $25.0^{\circ} \mathrm{C}$, by Grant et $a{ }^{6}{ }^{6}$ in water at several temperatures, by Etman and Naggar $^{7}$ in sugar aqueous solutions at 20.0 and $37.0^{\circ} \mathrm{C}$, by Bustamante and coworkers ${ }^{8}$ in ethanol + water, ethanol + ethyl acetate, and dioxane + water mixtures at several temperatures, and Martínez ${ }^{9}$ in propylene glycol + water mixtures at $25.0{ }^{\circ} \mathrm{C}$, among others.

\section{Experimental}

\section{Materials}

Acetaminophen USP (ACP); ${ }^{10}$ propylene glycol USP $(\mathrm{PG}) ;{ }^{10}$ distilled water $(\mathrm{W})$, conductivity $<2 \mu \mathrm{S}$, Laboratory of Pharmaceutics of the Universidad Nacional de Colombia; molecular sieve Merck (numbers 3 and 4); Millipore Corp. Swinnex ${ }^{\circledR}-13$ filter units.

\section{Equipment}

Mettler AE 160 digital analytical balance, sensitivity \pm $0.1 \mathrm{mg}$; Wrist Action, Burrel, model 75 mechanical shaker; Magni Whirl Blue M. Electric Company water baths, temperature control $\pm 0.05^{\circ} \mathrm{C}$; WTB Binder E28 sterilizer/ drying oven; DMA 45 Anton Paar digital density meter, precision $\pm 0.0001 \mathrm{~g} \mathrm{~cm}^{-3}$; Abbe Carlzeiss Jena refractive meter, precision \pm 0.0002 ; micro pipettes Nichiryo ${ }^{\circledR}$.

\section{Solubility determinations}

An excess of ACP was added to $20 \mathrm{~cm}^{3}$ of each cosolvent mixture evaluated in glass flasks. The cosolvent mixtures were prepared by mass in quantities close to $100.0 \mathrm{~g}$ varying in $10 \%, \mathrm{~m} / \mathrm{m}$. Solid-liquid mixtures were stirred in a mechanical shaker for 1 hour. Samples were then allowed to stand in water baths kept at the appropriate temperature $\pm 0.05^{\circ} \mathrm{C}$. All samples were maintained at least for 48 hours to reach the equilibrium. This equilibrium time was established in a previous investigation ${ }^{11}$ about the dissolution rate and solubility of ACP in EtOH, PG and $\mathrm{W}$ at $20.0^{\circ} \mathrm{C}$. After this time the supernatant solutions were filtered (at isothermal conditions) to ensure that they were free of particulate matter before sampling. Concentrations were determined by measuring refractive indexes after appropriate dilution and interpolation from previously constructed calibration curves for ACP in each cosolvent mixture. ${ }^{2}$ All the solubility experiments were repeated at least three times. In order to make the equivalence between molarity and mole fraction concentration scales, the density of the saturated solutions was determined with a digital density meter.

\section{Results and Discussion}

In Table 1, the molecular structure of ACP and some of their physicochemical properties are summarized. ${ }^{8,12,13}$ The melting point and enthalpy of fusion were reported by Bustamante and coworkers ${ }^{8}$ while the enthalpy of sublimation was reported by Williams et al. ${ }^{13}$ According to Romero et al. ${ }^{14}$ this drug acts in solution mainly as a Lewis acid in order to establish hydrogen bonds with proton-acceptor groups in the solvents (oxygen in -OH groups). Dearden ${ }^{15}$ demonstrated that both functional groups of this drug (-NH and $-\mathrm{OH}$ ) were involved in complex formation with the carbonyl group of antipyrine. ACP could also act as a proton-acceptor compound by means of its carbonyl and $-\mathrm{OH}$ moieties.

\section{Ideal and experimental solubility of ACP}

The ideal solubility of a crystalline solute in a liquid solvent can be calculated by equation (1):

$$
\ln X_{2}^{\text {id }}=-\frac{\Delta H_{\text {fus }}\left(T_{\text {fus }}-T\right)}{R T_{\text {fus }} T}+\left(\frac{\Delta C_{\mathrm{p}}}{R}\right)\left[\frac{\left(T_{\text {fus }}-T\right)}{T}+\ln \left(\frac{T}{T_{\text {fus }}}\right)\right]
$$

Table 1. Some physicochemical properties of ACP

\begin{tabular}{|c|c|c|c|c|}
\hline Molecular structure a & Molar mass $/ \mathrm{g} \mathrm{mol}^{-1}$ a & Melting point / $\mathrm{K}^{\mathrm{b}}$ & $\Delta H_{\mathrm{fus}} / \mathrm{kJ} \mathrm{mol} \mathrm{l}^{-1 \mathrm{~b}}$ & $\Delta H_{\text {subl }} / \mathrm{kJ} \mathrm{mol}^{-1 \mathrm{c}}$ \\
\hline$>\mathrm{NH}-\mathrm{CO}-\mathrm{CH}_{3}$ & 151.16 & 442.3 & 26.25 & 238.85 \\
\hline
\end{tabular}

a Taken from Ref. 12; ${ }^{\mathrm{b}}$ Taken from Ref. 8; ${ }^{\mathrm{c}}$ Taken from Ref. 13 
where $X_{2}^{\text {id }}$ is the ideal solubility of the solute as mole fraction, $\Delta H_{\text {fus }}$ is the molar enthalpy of fusion of the pure solute (at the melting point), $T_{\text {fus }}$ is the absolute melting point, $T$ is the absolute solution temperature, $R$ is the gas constant $\left(8.314 \mathrm{~J} \mathrm{~mol}^{-1} \mathrm{~K}^{-1}\right)$, and $\Delta C_{\mathrm{p}}$ is the difference between the molar heat capacity of the crystalline form and the molar heat capacity of the hypothetical supercooled liquid form, both at the solution temperature. ${ }^{16}$ Since $\Delta C_{\mathrm{p}}$ cannot be easily determined, one of the following assumptions has to be made: (a) $\Delta C_{\mathrm{p}}$ is negligible and can be considered zero or (b) $\Delta C_{\mathrm{p}}$ may be approximated to the entropy of fusion, $\Delta S_{\text {fus }}$. In this investigation the later consideration is assumed.

Table 2 summarizes the experimental solubilities of ACP, expressed as molarities and mole fractions, and the ideal solubilities calculated by means of equation (1) from $\Delta H_{\text {fus }}$, and $T_{\text {fus }}$ presented in Table 1. In all cases, the coefficients of variation for solubility were smaller than $2.0 \%$. On the other hand, Figure 1 shows the solubility expressed in mole fraction at all the studied temperatures. In this cosolvent system a maximum in solubility is not obtained in contrast to that found in other cosolvent systems such as ethanol + water $(\mathrm{EtOH}+\mathrm{W}){ }^{8}$

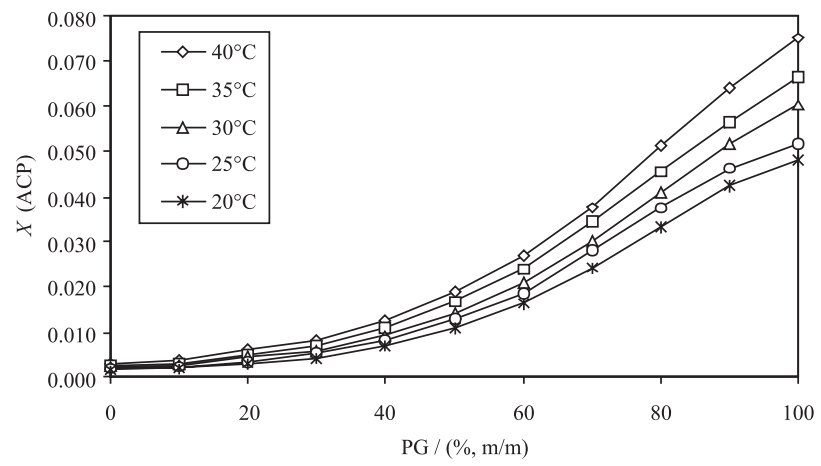

Figure 1. Solubility of ACP expressed in mole fraction in $\mathrm{PG}+\mathrm{W}$ cosolvent mixtures at several temperatures

The Hildebrand solubility parameter $(\delta)$ obtained for this drug in $\mathrm{EtOH}+\mathrm{W}$ mixtures was $28.3 \mathrm{MPa}^{1 / 2}(13.8$ $\mathrm{cal}^{1 / 2} \mathrm{~cm}^{-3 / 2}$ ) at $25.0{ }^{\circ} \mathrm{C} .{ }^{8}$ This value is outside of $\delta$ values obtained with $\mathrm{PG}+\mathrm{W}$ mixtures, i.e., from $30.3 \mathrm{MPa}^{1 / 2}$ $\left(14.8 \mathrm{cal}^{1 / 2} \mathrm{~cm}^{-3 / 2}\right)$ up to $47.9 \mathrm{MPa}^{1 / 2}\left(23.0 \mathrm{cal}^{1 / 2} \mathrm{~cm}^{-3 / 2}\right)$ For this reason, the solubility obtained in $\mathrm{EtOH}+\mathrm{W}$ mixtures is relatively larger in comparison with $\mathrm{PG}+\mathrm{W}$ mixtures. ${ }^{9}$ On the other hand, if molarity is considered, a maximum in solubility is obtained at $90 \%$ of PG at all temperatures.

Table 2. Experimental solubility of ACP in PG $+\mathrm{W}$ cosolvent mixtures expressed in mol $\mathrm{L}^{-1}$ and mole fraction including ideal solubility at several temperatures

\begin{tabular}{|c|c|c|c|c|c|}
\hline \multirow[t]{2}{*}{$\mathrm{PG} /(\%, \mathrm{~m} / \mathrm{m})$} & \multicolumn{5}{|c|}{$\mathrm{mol} \mathrm{L}^{-1}$ a } \\
\hline & $20.0^{\circ} \mathrm{C}$ & $25.0^{\circ} \mathrm{C}$ & $30.0^{\circ} \mathrm{C}$ & $35.0^{\circ} \mathrm{C}$ & $40.0^{\circ} \mathrm{C}$ \\
\hline 0 & 0.0837 & 0.1015 & 0.1141 & 0.1390 & 0.1701 \\
\hline 10 & 0.0959 & 0.1205 & 0.1397 & 0.161 & 0.193 \\
\hline 20 & 0.135 & 0.163 & 0.204 & 0.234 & 0.276 \\
\hline 30 & 0.173 & 0.223 & 0.247 & 0.286 & 0.327 \\
\hline 40 & 0.262 & 0.309 & 0.353 & 0.420 & 0.469 \\
\hline 50 & 0.373 & 0.440 & 0.469 & 0.554 & 0.624 \\
\hline 60 & 0.490 & 0.551 & 0.613 & 0.693 & 0.771 \\
\hline 70 & 0.622 & 0.707 & 0.751 & 0.851 & 0.923 \\
\hline 80 & 0.714 & 0.788 & 0.852 & 0.942 & 1.040 \\
\hline 90 & 0.733 & 0.793 & 0.872 & 0.949 & 1.063 \\
\hline 100 & 0.638 & 0.679 & 0.785 & 0.858 & 0.962 \\
\hline \multirow[t]{2}{*}{$\mathrm{PG} /(\%, \mathrm{~m} / \mathrm{m})$} & \multicolumn{5}{|c|}{ Mole fraction $\times 10^{2}$ a } \\
\hline & $20.0{ }^{\circ} \mathrm{C}$ & $25.0{ }^{\circ} \mathrm{C}$ & $30.0^{\circ} \mathrm{C}$ & $35.0{ }^{\circ} \mathrm{C}$ & $40.0^{\circ} \mathrm{C}$ \\
\hline 0 & 0.152 & 0.185 & 0.209 & 0.256 & 0.315 \\
\hline 10 & 0.188 & 0.237 & 0.276 & 0.319 & 0.384 \\
\hline 20 & 0.287 & 0.347 & 0.438 & 0.506 & 0.600 \\
\hline 30 & 0.403 & 0.522 & 0.581 & 0.677 & 0.780 \\
\hline 40 & 0.676 & 0.803 & 0.924 & 1.112 & 1.249 \\
\hline 50 & 1.086 & 1.294 & 1.385 & 1.66 & 1.89 \\
\hline 60 & 1.64 & 1.86 & 2.08 & 2.38 & 2.68 \\
\hline 70 & 2.43 & 2.80 & 3.00 & 3.44 & 3.77 \\
\hline 80 & 3.36 & 3.74 & 4.08 & 4.56 & 5.10 \\
\hline 90 & 4.26 & 4.64 & 5.16 & 5.67 & 6.42 \\
\hline 100 & 4.86 & 5.16 & 6.03 & 6.64 & 7.52 \\
\hline ideal & 5.308 & 5.989 & 6.744 & 7.580 & 8.503 \\
\hline
\end{tabular}

${ }^{\mathrm{a}}$ In all cases the coefficients of variation $(\mathrm{CV})$ were smaller than $2.0 \%$. 


\section{Thermodynamic functions of solution}

The making of weighted graphs based on the logarithm of solubility as a function of reciprocal absolute temperature permits to obtain the apparent enthalpic change of solution ( $\Delta H^{0}$ app $)$ by means of van't Hoff equation (equation 2):

$\left(\frac{\partial \ln X_{2}}{\partial(1 / T)}\right)_{P}=-\frac{\Delta H_{\mathrm{soln}}^{0 \text { app }}}{R}$

In more recent treatments, some corrections have been introduced to equation (2) in order to reduce the propagation of errors, and therefore, to separate the chemical effects from those due only to statistical treatments used in compensation plots. For this reason, the mean harmonic temperature $\left(T_{\mathrm{hm}}\right)$ is used in van' Hoff analysis. $T_{\mathrm{hm}}$ is calculated as: ${ }^{17}$

$$
T_{\mathrm{hm}}=\frac{n}{\sum_{i}^{n}(1 / T)}
$$

where $n$ is the number of tested temperatures. In our case the $T_{\mathrm{hm}}$ value obtained was just $303 \mathrm{~K}$. The corrected expression more widely used can be written as follows: ${ }^{8}$

$\left(\frac{\partial \ln X_{2}}{\partial\left(1 / T-1 / T_{\mathrm{hm}}\right)}\right)_{P}=-\frac{\Delta H_{\text {soln }}^{0 \text { app }}}{R}$

As an example, Figure 2 shows the modified van't Hoff plot for ACP in mixtures having $80 \%$ and $90 \%$ of PG. Linear models with good correlation coefficients were obtained in all mixtures studied. For this reason, the equation (4) is useful to estimate the $\Delta H_{\text {soln }}^{0}$ ap values for $\mathrm{ACP}$ in the $\mathrm{PG}+\mathrm{W}$ cosolvent system.

For non-ideal solutions, the slope obtained in equation (4) does not give directly the heat of solution. Therefore, it is necessary to consider the variation of solute

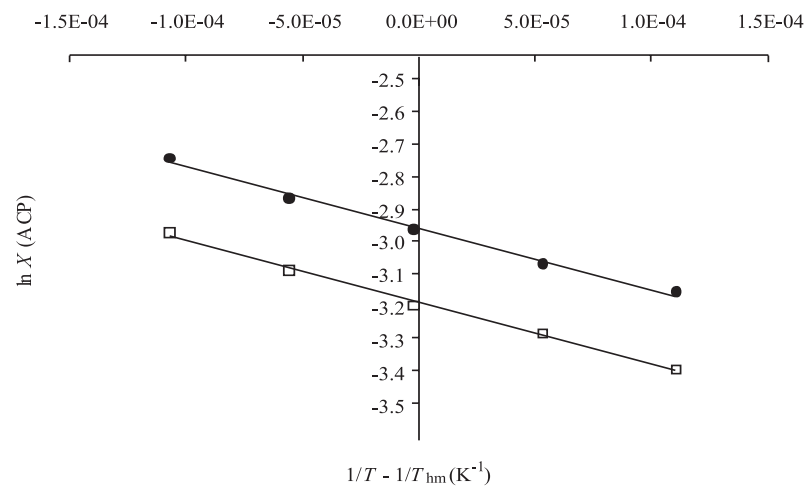

Figure 2. Temperature dependence for solubility of ACP expressed in mole fraction in some PG $+\mathrm{W}$ cosolvent mixtures (squares: $80 \%(\mathrm{~m} / \mathrm{m})$ of PG; solid circles: $90 \%(\mathrm{~m} / \mathrm{m})$ of PG). thermodynamic activity $\left(a_{2}\right)$ with concentration at constant temperature and pressure. ${ }^{8,18}$ Then, the enthalpic change of solution is calculated as:

$\Delta H_{\text {soln }}^{0}=\Delta H_{\text {soln }}^{0 \text { app }}\left(\frac{\partial \ln a_{2}}{\partial \ln X_{2}}\right)_{T, P}$

in which, the second term of the right side is calculated by means of: 8,19

$\left(\frac{\partial \ln a_{2}}{\partial \ln X_{2}}\right)_{T, p}=1-\frac{2 \phi_{2}}{X_{1}} \ln \left(\frac{a_{2}^{\text {sat }}}{X_{2}^{\text {sat }}}\right)$

The term "sat" indicates the saturation. In equation (6) the solute volumetric fraction $\left(\phi_{2}\right)$ is required. This property is calculated from the apparent specific volume of solute $\left(A S V_{2}\right)$ at saturation, and the mixture composition. $A S V_{2}$ is calculated by means of:

$A S V_{2}=\frac{m_{2}+m_{1}\left(1-S V_{1} \rho\right)}{m_{2} \rho}$

where, $m_{2}$ and $m_{1}$ are the masses of solute and solvent at saturation, respectively, $S V_{1}$ is the specific volume of solvent, and $\rho$ is the solution density. Although in a more refined treatment, the partial specific volume of solute instead of $A S V_{2}$ should be used, the procedure proposed here is also adequate.

Since ACP is a solid, the thermodynamic activity at saturation equals the ideal solubility $\left(X_{2}^{\text {id }}\right)^{3}$ and therefore, it follows that:

$\left(\frac{\partial \ln a_{2}}{\partial \ln X_{2}}\right)_{T, p}=1-\frac{2 \phi_{2}}{X_{1}} \ln \left(\frac{X_{2}^{\mathrm{id}}}{X_{2}^{\mathrm{sat}}}\right)$

The term $\left(X_{2}^{\text {id } / ~} X_{2}^{\text {sat }}\right)$ in equation (8) is equal to the solute activity coefficient in the solution $\left(\gamma_{2}\right)$ and it is an indication of the deviation presented by this one in front to ideal behavior. Table 3 shows the experimental \% $(\mathrm{m} / \mathrm{v})$ solubilities, saturated solution densities, cosolvent mixtures densities, solute volume fractions, solute activity coefficients, and correction factors at $30.0{ }^{\circ} \mathrm{C}$. This temperature is the nearest to $303 \mathrm{~K}$. In order to calculate the $\gamma_{2}$ and $\left(\partial \ln a_{2} / \partial \ln X_{2}\right)_{T, p}$ values some methods for estimating propagation of errors were used. ${ }^{20}$

From the $\gamma_{2}$ values presented in Table 3 a rough estimate of solute-solvent intermolecular interactions can be made by considering the following expression:

$\ln \gamma_{2}=\left(w_{11}+w_{22}-2 w_{12}\right) \frac{V_{2} \phi_{1}^{2}}{R T}$ 
Table 3. Solubility of ACP expressed in \% (m/v), saturated solution and solvent densities, solute volumetric fraction, solute activity coefficient, and activity variation factor in $\mathrm{PG}+\mathrm{W}$ cosolvent mixtures at $30.0^{\circ} \mathrm{C}$

\begin{tabular}{|c|c|c|c|c|c|c|}
\hline $\mathrm{PG} /(\%, \mathrm{~m} / \mathrm{m})$ & $\mathrm{ACP} /(\%, \mathrm{~m} / \mathrm{v})^{\mathrm{a}}$ & $\rho /\left(\mathrm{g} \mathrm{cm}^{-3}\right)^{\mathrm{b}}$ & $\rho_{0} /\left(\mathrm{g} \mathrm{cm}^{-3}\right)^{\mathrm{b}}$ & $\phi_{2}$ & $\gamma_{2}$ & $\frac{\partial \ln a_{2}}{\partial \ln X_{2}}$ \\
\hline 0 & 1.72 & 0.9990 & 0.9957 & 0.0140 & 32.3 & 0.902 \\
\hline 10 & 2.11 & 1.0071 & 1.0026 & 0.0166 & 24.5 & 0.894 \\
\hline 20 & 3.08 & 1.0161 & 1.0106 & 0.0250 & 15.4 & 0.862 \\
\hline 30 & 3.73 & 1.0256 & 1.0187 & 0.0299 & 11.6 & 0.853 \\
\hline 40 & 5.33 & 1.0347 & 1.0257 & $0 . .0432$ & 7.30 & 0.827 \\
\hline 50 & 7.08 & 1.0428 & 1.0316 & 0.0578 & 4.87 & 0.814 \\
\hline 60 & 9.26 & 1.0494 & 1.0348 & 0.0754 & 3.24 & 0.819 \\
\hline 70 & 11.35 & 1.0539 & 1.0368 & 0.0929 & 2.25 & 0.844 \\
\hline 80 & 12.88 & 1.0559 & 1.0358 & 0.1050 & 1.65 & 0.890 \\
\hline 90 & 13.19 & 1.0545 & 1.0335 & 0.1073 & 1.31 & 0.939 \\
\hline 100 & 11.86 & 1.0491 & 1.0289 & 0.0957 & 1.12 & 0.977 \\
\hline
\end{tabular}

${ }^{\mathrm{a}}$ In all cases CV were smaller than $2.0 \%{ }^{\mathrm{b}}$ In all cases standard deviations were smaller than $0.0002 \mathrm{~g} \mathrm{~cm}^{-3}$.

where $w_{11}, w_{22}$ and $w_{12}$ represent the solvent-solvent, solutesolute and solvent-solute interaction energies, respectively; $V_{2}$ is the molar volume of the supercooled liquid solute, and finally, $\phi_{1}$ is the volume fraction of the solvent. In a first approach the term $\left(V_{2} \phi_{1}^{2} / R T\right)$ may be considered approximately constant at the same temperature, and then $\gamma_{2}$ depends almost exclusively on $w_{11}, w_{22}$ and $w_{12}{ }^{21}$ The $w_{11}$ and $w_{22}$ terms are unfavorable for solubility, while the $w_{12}$ term favors the solution process.

It can be seen in equation (9) that the contribution of $w_{22}$ represents the work necessary to move molecules from solid state to the vapor state, and therefore it is constant in all mixtures. On the other hand, Romero et al. ${ }^{22}$ have demonstrate recently by using calorimetric, spectroscopic, and crystallographic techniques, that ACP solid phase in excess keeps its original crystalline properties in saturated solutions in several cosolvent mixtures varying in polarity and Lewis acid-base character. Although, an increase of $8^{\circ} \mathrm{C}$ in the melting point has been reported for ACP solid phase at equilibrium with saturated solutions having cosolvent proportions greater than $50 \%(\mathrm{v} / \mathrm{v}),{ }^{8}$ according to these authors, for practical purposes it may be considered that the contribution of solid phase toward the overall solution process is constant for this drug in the different saturated solutions studied.

The term $w_{11}$ is higher in water $\left(\delta=47.9 \mathrm{MPa}^{1 / 2}\right)$ while it is comparatively smaller in PG $\left.\left(\delta=30.3 \mathrm{MPa}^{1 / 2}\right)\right)^{23}$ The pure water and water-rich mixtures have larger $\gamma_{2}$ values, which means, high $w_{11}$ and low $w_{12}$ values. On the other hand, in PG-rich mixtures (with $\gamma_{2}$ values close to 1.0), the $w_{11}$ values are relatively low, whereas the $w_{12}$ values are higher. According to this fact, the solvation of ACP should be higher in PG-rich mixtures.

The apparent standard Gibbs energy change for the solution process $\left(\Delta G_{\mathrm{soln}}^{0 \text { app }}\right)$ has been traditionally calculated in literature as: $:^{21}$
$\Delta G_{\text {soln }}^{0 \text { app }}=-R T \ln X_{2}$

Nevertheless considering the approach proposed by Krug et al.,${ }^{13}$ this property is more appropriately calculated by means of:

$\Delta G_{\mathrm{soln}}^{0 \text { app }}=-R T_{\mathrm{hm}} \times$ intercept

in which, the intercept used is the one obtained from $\ln$ $X_{2}$ vs. $1 / T-1 / T_{\mathrm{hm}}$ plots (equation 4$)$. This thermodynamic function is also corrected using the factor $\left(\partial \ln a_{2} / \partial \ln X_{2}\right)_{T, P}$ in order to express it in terms of solute thermodynamic activity instead of solute concentration.

The standard entropic change for solution process $\left(\Delta S_{\text {soln }}^{0}\right)$ is obtained from the respective $\Delta H_{\text {soln }}^{0}$ and $\Delta G_{\text {soln }}^{0}$ values by using:

$\Delta S_{\text {soln }}^{0}=\frac{\left(\Delta H_{\text {soln }}^{0}-\Delta G_{\text {soln }}^{0}\right)}{T_{\mathrm{hm}}}$

Table 4 summarizes the corrected standard thermodynamic functions for experimental solution process of $\mathrm{ACP}$ in all cosolvent mixtures including those functions for the ideal process. In order to calculate the thermodynamic magnitudes of experimental solution some methods for estimating propagation of errors were used..$^{20}$ It was found that the standard Gibbs energy of solution was positive in all cases; i.e., the solution process apparently is not spontaneous, which may be explained in terms of the concentration scale used (mole fraction), where the reference state is the ideal solution having the unity as concentration of ACP, that is, the solid pure solute.

The enthalpy of solution is positive for all cases, therefore the process is always endothermic. The entropy of solution is also positive in all cases, indicating entropy driving on overall the solution processes. The 
Table 4. Thermodynamic functions relative to solution process of ACP in PG $+\mathrm{W}$ cosolvent mixtures including ideal process at $303 \mathrm{~K}$

\begin{tabular}{|c|c|c|c|c|c|c|}
\hline $\mathrm{PG} /(\%, \mathrm{~m} / \mathrm{m})$ & $\Delta G_{\mathrm{soln}}^{0} /\left(\mathrm{kJ} \mathrm{mol}^{-1}\right)$ & $\Delta H_{\mathrm{soln}}^{0} /\left(\mathrm{kJ} \mathrm{mol}^{-1}\right)$ & $\Delta S_{\text {soln }}^{0} /\left(\mathrm{J} \mathrm{mol}^{-1} \mathrm{~K}^{-1}\right)$ & $T \Delta S_{\mathrm{soln}}^{0} /\left(\mathrm{kJ} \mathrm{mol}^{-1}\right)$ & $\% \xi_{H}{ }^{a}$ & $\% \xi_{T S}{ }^{\mathrm{a}}$ \\
\hline 0 & $13.95(0.28)$ & $24.4(0.8)$ & $34.4(1.3)$ & $10.4(0.4)$ & 70.0 & 30.0 \\
\hline 10 & $13.29(0.27)$ & $23.6(0.7)$ & $34.0(1.2)$ & $10.3(0.4)$ & 69.6 & 30.4 \\
\hline 20 & $11.88(0.24)$ & $24.4(0.6)$ & $41.4(1.3)$ & $12.5(0.4)$ & 66.1 & 33.9 \\
\hline 30 & $11.07(0.22)$ & $20.6(0.9)$ & $31.5(1.5)$ & $9.6(0.5)$ & 68.3 & 31.7 \\
\hline 40 & $9.74(0.19)$ & $19.6(0.5)$ & $32.5(1.1)$ & $9.9(0.4)$ & 66.5 & 33.5 \\
\hline 50 & $8.71(0.17)$ & $16.8(0.7)$ & $26.7(1.2)$ & $8.1(0.4)$ & 67.5 & 32.5 \\
\hline 60 & $7.95(0.16)$ & $15.5(0.4)$ & $24.8(0.8)$ & $7.5(0.3)$ & 67.4 & 32.6 \\
\hline 70 & $7.42(0.15)$ & $13.9(0.6)$ & $21.5(1.0)$ & $6.5(0.3)$ & 68.2 & 31.8 \\
\hline 80 & $7.15(0.14)$ & $14.1(0.5)$ & $22.9(0.9)$ & $6.9(0.3)$ & 67.0 & 33.0 \\
\hline 90 & $7.01(0.14)$ & $14.6(0.6)$ & 25.1 & $7.6(0.3)$ & 65.7 & 34.3 \\
\hline 100 & $6.94(0.14)$ & $17.0(0.7)$ & $33.1(1.5)$ & $10.0(0.5)$ & 62.9 & 37.1 \\
\hline ideal & 6.80 & 17.98 & 36.90 & 11.18 & 61.7 & 38.4 \\
\hline
\end{tabular}

a $\% \zeta_{H}$ and $\% \zeta_{T S}$ are the relative contributions by enthalpy and entropy toward Gibbs energy of solution. These values were calculated by means of equations (13) and (14), respectively.

$\Delta H_{\text {soln }}^{0}$ value in water is in good agreement with those presented by Grant et al. ${ }^{6}$ and Bustamante and coworkers, ${ }^{8}$ that is, 23.7 and $22.5 \mathrm{~kJ} \mathrm{~mol}^{-1}$, respectively. The $\Delta H_{\text {soln }}^{0}$ values vary nonlinearly with PG composition showing a maximum at $20 \%(\mathrm{~m} / \mathrm{m})$ of cosolvent.

With the aim to compare the relative contributions by enthalpy $\left(\% \zeta_{H}\right)$ and by entropy $\left(\% \zeta_{T S}\right)$ toward the solution process, equations (13) and (14) were employed respectively.

$\% \zeta_{H}=100 \frac{\left|\Delta H_{\text {soln }}^{0}\right|}{\left|\Delta H_{\text {soln }}^{0}\right|+\left|T \Delta S_{\text {soln }}^{0}\right|}$

$\% \zeta_{T S}=100 \frac{\left|T \Delta S_{\text {soln }}^{0}\right|}{\left|\Delta H_{\text {soln }}^{0}\right|+\left|T \Delta S_{\text {soln }}^{0}\right|}$

From Table 4 it follows that in all cases the main contributor to standard free energy of solution process of $\mathrm{ACP}$ is the enthalpy (greater than $62 \%$ in all cases).

\section{Thermodynamic functions of mixing}

The solution process may be represented by the following hypothetic stages: ${ }^{21}$

$$
\text { Solute }_{\text {(Solid) }} \rightarrow \text { Solute }_{\text {(Liquid) }} \rightarrow \text { Solute }_{\text {(Solution) }}
$$

where, fusion and mixing are the respective partial processes toward the solution process at $303 \mathrm{~K}$. This approximation permits to calculate the partial thermodynamic contributions to solution process by means of equations (15) and (16).

$\Delta H_{\text {soln }}^{0}=\Delta H_{\text {fus }}^{303}+\Delta H_{\text {mix }}^{0}$
$\Delta S_{\text {soln }}^{0}=\Delta S_{\text {fus }}^{303}+\Delta S_{\text {mix }}^{0}$

where, $\Delta H_{\text {fus }}^{303}$ and $\Delta S_{\text {fus }}^{303}$ represent the thermodynamic functions of fusion process at harmonic temperature (303 $\mathrm{K}) . \Delta H_{\text {fus }}^{303}$ was calculated from $\Delta H_{\text {fus }}^{\mathrm{T}}=\Delta H_{\text {fus }}^{\mathrm{MP}}-\Delta C_{\mathrm{p}}\left(T_{\text {fus }}\right.$ - T) using $\Delta S_{\text {fus }}^{\mathrm{MP}}$ instead of $\Delta C_{\mathrm{p}}$ obtaining a value of 17.98 $\mathrm{kJ} \mathrm{mol}^{-1}$. This value is coincident with the enthalpic change for ideal solution. In contrast, the entropy of fusion at $303 \mathrm{~K}\left(59.35 \mathrm{~J} \mathrm{~mol}^{-1} \mathrm{~K}^{-1}\right)$ is not coincident with the entropy of ideal solution at this temperature $\left(36.90 \mathrm{~J} \mathrm{~mol}^{-1} \mathrm{~K}^{-1}\right)$. Nevertheless, for practical purposes, the $\Delta S_{\mathrm{soln}}^{0 \text { id }}$ value was used instead of $\Delta S_{\text {fus. }}^{303}$. In Table 5 the thermodynamic functions of mixing of ACP are summarized.

By analyzing the partial contributions by ideal solution (related to solute fusion process) and mixing processes to the enthalpy and entropy of solution, it is found that $\Delta H_{\text {fus }}^{303}$ and $\Delta S_{\text {fus }}^{303}$ are positive (Table 4). On the other hand, the contribution of the thermodynamic functions relative to mixing process toward the solution process is variable, that is, $\Delta H_{\text {mix }}^{0}$ is positive in those mixtures with PG content equal or lower than $40 \%$ and negative for all other mixtures, while the entropy of mixing ( $\Delta S_{\text {mix }}^{0}$ ) is positive in the mixture containing $20 \%$ of PG, but negative in all other mixtures. Therefore, the entropies of mixing are in general unfavorable (negative values: Table 5). However, considering the overall solution process (that is, data from Table 4), entropy change is the driven force (positive values: Table 4) because the solution process includes the favorable entropy of melting (positive value: Table 4).

The net variation in $\Delta H_{\text {mix }}^{0}$ values results from the contribution of several kinds of interactions. The enthalpy of cavity formation is endothermic because energy must be supplied to overcome the cohesive forces of the solvent. This process decreases solubility. On the other hand, the enthalpy of solute-solvent interaction is exothermic and it is originated mainly from the van der Waals and Lewis acid-base 
Table 5. Thermodynamic functions relative to mixing process of ACP in PG $+\mathrm{W}$ cosolvent mixtures at $303 \mathrm{~K}$

\begin{tabular}{|c|c|c|c|c|c|c|}
\hline $\mathrm{PG} /(\%, \mathrm{~m} / \mathrm{m})$ & $\Delta G_{\mathrm{mix}}^{0} /\left(\mathrm{kJ} \mathrm{mol}^{-1}\right)$ & $\Delta H_{\text {mix }}^{0} /\left(\mathrm{kJ} \mathrm{mol}^{-1}\right)$ & $\Delta S_{\text {mix }}^{0} /\left(\mathrm{J} \mathrm{mol}^{-1} \mathrm{~K}^{-1}\right)$ & $T \Delta S_{\operatorname{mix}}^{0} /\left(\mathrm{kJ} \mathrm{mol}^{-1}\right)$ & $\% \zeta_{H}{ }^{a}$ & $\% \xi_{T S}^{\mathrm{a}}$ \\
\hline 0 & 7.15 & 6.4 & -2.5 & -0.8 & 89.5 & 10.5 \\
\hline 10 & 6.50 & 5.6 & -2.9 & -0.9 & 86.3 & 13.7 \\
\hline 20 & 5.09 & 6.5 & 4.5 & 1.4 & 82.5 & 17.5 \\
\hline 30 & 4.27 & 2.6 & -5.4 & -1.6 & 62.0 & 38.0 \\
\hline 40 & 2.94 & 1.6 & -4.4 & -1.3 & 55.2 & 44.8 \\
\hline 50 & 1.91 & -1.2 & -10.2 & -3.1 & 27.6 & 72.4 \\
\hline 60 & 1.18 & -2.5 & -12.1 & -3.7 & 40.5 & 59.5 \\
\hline 70 & 0.63 & -4.1 & -15.4 & -4.7 & 46.4 & 53.6 \\
\hline 80 & 0.35 & -3.9 & -14.0 & -4.3 & 47.8 & 52.2 \\
\hline 90 & 0.21 & -3.4 & -11.8 & -3.6 & 48.5 & 51.5 \\
\hline 100 & 0.15 & -1.0 & -3.8 & -1.2 & 46.6 & 53.4 \\
\hline
\end{tabular}

a $\% \zeta_{H}$ and $\% \zeta_{T S}$ are the relative contributions by enthalpy and entropy toward Gibbs energy of mixing. These values were calculated by means of equations (13) and (14), respectively.

interactions. The structuring of water molecules around the nonpolar groups of solutes (hydrophobic hydration) contributes to decrease the net heat of mixing to small or even negative values in aqueous solutions. Nevertheless, this is not observed in the case of ACP in water (Table 5). As it was already said, the energy of cavity formation should be lower as the proportion of PG increases because the polarity of the medium decreases, which favors solute-solvent interactions. This fact is partially observed in Table 5, where $\Delta H_{\text {mix }}^{0}$ is more negative over $50 \%$ of cosolvent with a maximum at $70 \%$ of PG. According to Romero et al. ${ }^{14}$ in the initial portion of the solubility curve, the hydrogen bonding of ACP will increases with cosolvent concentration. At large cosolvent proportions, this interaction may be saturated, becoming a constant contribution. On the other hand, nonspecific and cavity effects are not saturated and vary with cosolvent concentration.

For comparative purposes, Figure 3 shows the thermodynamic functions of mixing, $\Delta G_{\text {mix }}^{0}, \Delta H_{\text {mix }}^{0}$, and $T \Delta S_{\mathrm{mix}}^{0}$. All functions vary nonlinearly with composition showing maxima for enthalpy and entropy at $20 \%$ of PG.

In order to verify the effect of cosolvent composition on the thermodynamic function driving the solution process Table 6 summarizes the thermodynamic functions of transfer of ACP from more polar solvents

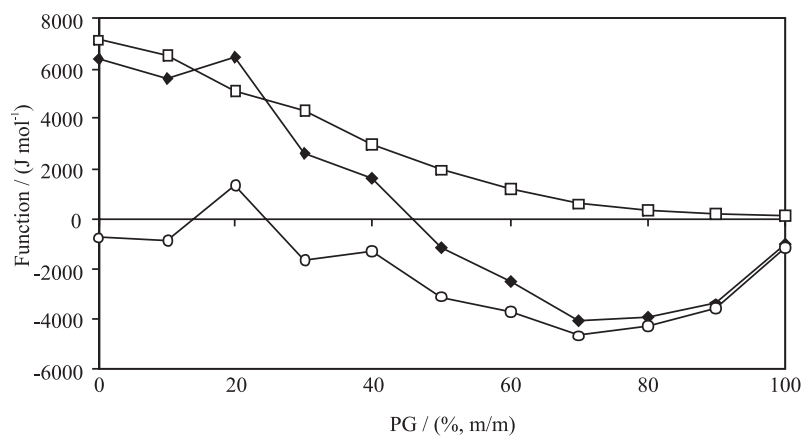

Figure 3. Thermodynamic functions, relative to mixing process of ACP in PG + W cosolvent mixtures at $303 \mathrm{~K}$; (squares: $\Delta G_{\text {mix }}^{0}$; solid diamond: $\Delta H_{\text {mix }}^{0}$; circles: $T \Delta S_{\text {mix }}^{0}$ ). to those less polar solvents. These new functions were calculated as the differences in thermodynamic magnitudes of mixing between the less polar mixtures and the more polar mixtures. As a calculation example, in the case of transfer of ACP from pure water to $10 \%$ PG mixture (considering data of Table 5), the enthalpy of transfer $\left(\Delta H_{1 \rightarrow 2}^{0}\right)$ corresponds to $5.6 \mathrm{~kJ} \mathrm{~mol}^{-1}\left(\Delta H_{\text {mix }}^{0}\right.$ in $10 \% \mathrm{PG}$ mixture) minus $6.4 \mathrm{~kJ} \mathrm{~mol}^{-1}\left(\Delta H_{\text {mix }}^{0}\right.$ in pure water) obtaining the value: $-0.8 \mathrm{~kJ} \mathrm{~mol}^{-1}$ (Table 6). All other thermodynamic magnitudes of transfer were calculated on the same way.

If the addition of $\mathrm{PG}$ to water is considered, it happens the following: At $10 \%$ of PG $\left(\Delta G_{\mapsto \rightarrow 2}^{0}<0\right.$ and $\left.\Delta H_{\mapsto \rightarrow 2}^{0}<0\right)$, the solution process is driven by enthalpy, which it is not easily explained. For ACP solubility in $\mathrm{EtOH}+\mathrm{W}$ mixtures near to this composition the solution process was driven by entropy. ${ }^{8}$ At $20 \%$ of $\mathrm{PG}\left(\Delta G_{\mapsto \rightarrow 2}^{0}<0\right.$ and $\left.\Delta H_{\mapsto \rightarrow 2}^{0}>0\right)$ the solubility process is driven by the increment of entropy $\left(\Delta S_{\mapsto \rightarrow 2}^{0}>0\right)$. This suggests a decrease of the hydrophobic effect of water, produced by the addition of $20 \%$ of cosolvent. That is, the cosolvent disrupts the ordered structure of water (like "icebergs", waterwater hydrogen bonds) around de nonpolar groups of the drug, increasing the enthalpy and entropy of the system. From $30 \%$ up to $70 \%$ of PG $\left(\Delta G_{\mapsto \rightarrow 2}^{0}<0\right.$ and $\left.\Delta H_{\mapsto \rightarrow 2}^{0}<0\right)$ the solution processes are driven by enthalpy; this fact is probably due to solvation of ACP. In the mixture of $40 \%$ of PG in addition to enthalpy of mixing the entropy of mixing also contributes to solution process. Finally, from $80 \%$ up to $100 \%$ of PG $\left(\Delta G_{\mapsto \rightarrow 2}^{0}<0\right.$ and $\Delta H_{\mapsto \rightarrow 2}^{0}>0$ ) the entropy of mixing drives the solution process, because this property is positive and therefore it is favorable.

\section{Thermodynamic functions of solvation}

In addition to the hypothetic fusion-mixing stages previously exposed, the solution process may also be represented by the following hypothetic stages: ${ }^{24}$ 
Table 6. Thermodynamic functions of transfer of ACP from more polar solvents to less polar solvents in PG + W cosolvent mixtures at $303 \mathrm{~K}$

\begin{tabular}{|c|c|c|c|c|c|}
\hline \multicolumn{2}{|c|}{$\mathrm{PG} /(\%, \mathrm{~m} / \mathrm{m})$} & \multirow[t]{2}{*}{$\Delta G_{1 \rightarrow 2}^{0} /\left(\mathrm{kJ} \mathrm{mol}^{-1}\right)$} & \multirow[t]{2}{*}{$\Delta H_{1 \rightarrow 2}^{0} /\left(\mathrm{kJ} \mathrm{mol}^{-1}\right)$} & \multirow[t]{2}{*}{$\Delta S_{1 \rightarrow 2}^{0} /\left(\mathrm{J} \mathrm{mol}^{-1} \mathrm{~K}^{-1}\right)$} & \multirow[t]{2}{*}{$T \Delta S_{1 \rightarrow 2}^{0} /\left(\mathrm{kJ} \mathrm{mol}^{-1}\right)$} \\
\hline Medium 1 & Medium 2 & & & & \\
\hline 0 & 10 & -0.65 & -0.8 & -0.4 & -0.1 \\
\hline 10 & 20 & -1.41 & 0.8 & 7.4 & 2.3 \\
\hline 20 & 30 & -0.82 & -3.8 & -9.9 & -3.0 \\
\hline 30 & 40 & -1.33 & -1.0 & 1.0 & 0.3 \\
\hline 40 & 50 & -1.03 & -2.8 & -5.8 & -1.8 \\
\hline 50 & 60 & -0.73 & -1.3 & -1.9 & -0.6 \\
\hline 60 & 70 & -0.55 & -1.6 & -3.3 & -1.0 \\
\hline 70 & 80 & -0.27 & 0.2 & 1.4 & 0.4 \\
\hline 80 & 90 & -0.14 & 0.5 & 2.3 & 0.7 \\
\hline 90 & 100 & -0.06 & 2.3 & 7.9 & 2.4 \\
\hline
\end{tabular}

These magnitudes were calculated as $\Delta \Psi_{1 \rightarrow 2}^{0}=\Delta \Psi_{\mathrm{m}}^{0}$ $-\Delta \Psi_{\text {mix }}^{0}$ , where $\Psi$ is $G, H$ or $S$.

$$
\text { Solute }_{\text {(Solid) }} \rightarrow \text { Solute }_{\text {(Vapor) }} \rightarrow \text { Solute }_{(\text {Solution) }}
$$

where, the respective partial processes toward the solution process, are in this case, sublimation and solvation. This treatment permits calculate the partial thermodynamic contributions to solution process by means of equations (17) and (18), respectively, while the Gibbs energy of solvation is calculate by means of equation (19):

$\Delta H_{\text {soln }}^{0}=\Delta H_{\text {subl }}^{0}+\Delta H_{\text {solv }}^{0}$

$\Delta S_{\text {soln }}^{0}=\Delta S_{\text {subl }}^{0}+\Delta S_{\text {solv }}^{0}$

$\Delta G_{\text {soln }}^{0}=\Delta G_{\text {subl }}^{0}+\Delta G_{\text {solv }}^{0}$

where, $\Delta H_{\text {subl }}^{0}=238.85 \mathrm{~kJ} \mathrm{~mol}^{-1}$ was taken from Williams et al. ${ }^{13}$ and therefore, the function $\Delta H_{\text {solv }}^{0}$ was calculated from $\Delta H_{\text {soln }}^{0}$ values presented in Table 4 . The respective entropy of sublimation was calculated as $\Delta S_{\text {subl }}^{0}=\left(\Delta H_{\text {subl }}^{0}-\right.$ $\Delta G_{\text {subl }}^{0} / T$ at $303 \mathrm{~K}$, where $\Delta G_{\text {subl }}^{0}=-R T \ln \left(p / p_{0}\right)$ with $p=$ $1.05 \times 10^{-6} \mathrm{~Pa}$ at $303 \mathrm{~K}$ (calculated from some values presented by Williams et al..$^{9}$ ) and $p_{0}=101325 \mathrm{~Pa}$; then $\Delta G_{\text {subl }}^{0}=63.71 \mathrm{~kJ} \mathrm{~mol}^{-1}$, and therefore $\Delta S_{\text {subl }}^{0}=577.7 \mathrm{~J}$ $\mathrm{mol}^{-1} \mathrm{~K}^{-1}$ at the same temperature. In Table 7 the thermodynamic functions of solvation are presented, while on the other hand, with the aim to compare the relative contributions by enthalpy $\left(\% \zeta_{H}\right)$ and entropy $\left(\% \zeta_{T S}\right)$ toward the solvation process, two equations analogous to equations (13) and (14) were employed.

From the values of $\% \zeta_{H}$ and $\% \zeta_{T S}$ presented in Table 7 it follows that the main contributing force to standard Gibbs energy of the solvation process of ACP in all the cosolvent mixtures is the enthalpy $\left(\% \zeta_{H}\right.$ are greater than $56 \%$ in all cases).
Because that not only the main driving force of solvation process of drug compounds is important, but also the balance between specific and non-specific solutesolvent interactions as well, therefore, parameters which describe the relative ratio of specific and non-specific solute-solvent interaction in terms of enthalpies $\left(\% \varepsilon_{H}\right)$ and in terms of entropies $\left(\% \varepsilon_{S}\right)$, were used according to the following definitions introduced by Perlovich and coworkers: ${ }^{24}$

$$
\begin{aligned}
& \% \varepsilon_{H}=100\left|\frac{\Delta H_{\text {spec }}^{0}}{\Delta H_{\text {non-spec }}^{0}}\right| \\
& \% \varepsilon_{S}=100\left|\frac{\Delta S_{\text {spec }}^{0}}{\Delta S_{\text {non-spec }}^{0}}\right|
\end{aligned}
$$

where,

$$
\begin{aligned}
& \Delta H_{\text {spec }}^{0}=\Delta H_{\text {soln(solventi) }}^{0}-\Delta H_{\text {soln(cyclohex })}^{0}=\Delta H_{\text {soln(cyclohex } \rightarrow \text { solvent-i) }}^{0} \\
& \Delta H_{\text {non-spec }}^{0}=\Delta H_{\text {soln(cyclohex) }}^{0}-\Delta H_{\text {subl }}^{0}=\Delta H_{\text {solv(cyclohex) }}^{0} \\
& \Delta S_{\text {spec }}^{0}=\Delta S_{\text {soln(solvent-i) }}^{0}-\Delta S_{\text {soln(cyclohex) }}^{0}=\Delta S_{\text {soln(cyclohex } \rightarrow \text { solvent-i) }}^{0} \\
& \Delta S_{\text {non-s pec }}^{0}=\Delta S_{\text {soln(cyclohex) }}^{0}
\end{aligned}
$$

Cyclohexane was chosen as an "inert" solvent, which interacts with drug molecules solely by nonspecific interactions (dispersion forces), while the cosolvent mixtures interact with ACP by specific interactions such as hydrogen bonding. Benzene and hexane have also been used as inert solvents in the study of naproxen although important differences have been found between these two solvents, indicating some effect of $\pi$ electrons and planar geometry of benzene on non-specific interactions of that drug. ${ }^{24}$

Solubility data for ACP in cyclohexane taken from Baena et al. ${ }^{25}$ were analyzed according to equations (4), 
Table 7. Thermodynamic functions relative to solvation process of ACP in $\mathrm{PG}+\mathrm{W}$ cosolvent mixtures at $303 \mathrm{~K}$

\begin{tabular}{|c|c|c|c|c|c|c|c|c|}
\hline $\mathrm{PG} /(\%, \mathrm{~m} / \mathrm{m})$ & $\Delta G_{\mathrm{solv}}^{0} /\left(\mathrm{kJ} \mathrm{mol}^{-1}\right)$ & $\Delta H_{\mathrm{solv}}^{0} /\left(\mathrm{kJ} \mathrm{mol}^{-1}\right)$ & $\Delta S_{\text {solv }}^{0} /\left(\mathrm{J} \mathrm{mol}^{-1} \mathrm{~K}^{-1}\right)$ & $T \Delta S_{\mathrm{solv}}^{0} /\left(\mathrm{kJ} \mathrm{mol}^{-1}\right)$ & $\% \zeta_{H}{ }^{a}$ & $\% \zeta_{T S}^{\mathrm{a}}$ & $\% \varepsilon_{H}{ }^{\mathrm{b}}$ & $\% \varepsilon_{S}{ }^{\mathrm{b}}$ \\
\hline 0 & -49.76 & -214.5 & -543.3 & -164.6 & 56.6 & 43.4 & 6.8 & 1.2 \\
\hline 10 & -50.41 & -215.3 & -543.8 & -164.8 & 56.6 & 43.4 & 7.2 & 1.2 \\
\hline 20 & -51.82 & -214.4 & -536.3 & -162.5 & 56.9 & 43.1 & 6.8 & 0.0 \\
\hline 30 & -52.64 & -218.2 & -546.2 & -165.5 & 56.9 & 43.1 & 8.7 & 1.7 \\
\hline 40 & -53.97 & -219.2 & -545.2 & -165.2 & 57.0 & 43.0 & 9.2 & 1.5 \\
\hline 50 & -55.00 & -222.1 & -551.0 & -167.0 & 57.1 & 42.9 & 10.6 & 2.5 \\
\hline 60 & -55.73 & -223.4 & -553.0 & -167.5 & 57.1 & 42.9 & 11.3 & 2.8 \\
\hline 70 & -56.29 & -224.9 & -556.3 & -168.6 & 57.2 & 42.8 & 12.0 & 3.4 \\
\hline 80 & -56.56 & -224.8 & -554.9 & -168.1 & 57.2 & 42.8 & 12.0 & 3.2 \\
\hline 90 & -56.70 & -224.2 & -552.6 & -167.4 & 57.2 & 42.8 & 11.7 & 2.8 \\
\hline 100 & -56.76 & -221.9 & -544.6 & -165.0 & 57.3 & 42.7 & 10.5 & 1.4 \\
\hline
\end{tabular}

a $\% \zeta_{H}$ and $\% \zeta_{T S}$ are the relative contributions by enthalpy and entropy toward Gibbs energy of solvation. These values were calculated by means of equations (13) and (14), respectively; ${ }^{\mathrm{b}} \% \varepsilon_{H}$ and $\% \varepsilon_{S}$ are the relative ratio of specific and non specific solute-solvent interactions expressed in terms of enthalpy and entropy. These values were calculated by means of equations (20) to (25).

(11), and (12) founding the following values for apparent thermodynamic functions: $\Delta H_{\text {soln }(\mathrm{CH})}^{0 \text { ap }}=38.1 \mathrm{~kJ} \mathrm{~mol}^{-1}$, $\Delta G_{\text {soln }(\mathrm{CH})}^{0 \text { app }}=25.61 \mathrm{~kJ} \mathrm{~mol}^{-1}$, and $\Delta S_{\text {soln }(\mathrm{CH})}^{0 \text { app }}=41.2 \mathrm{~J} \mathrm{~mol}^{-1}$ $\mathrm{K}^{-1}$. The apparent specific volume of ACP in cyclohexane obtained by using densities of solvent and saturated solutions was a negative value (due to very scarce solubility and uncertainty in density measurements). For this reason, in order to calculate the $\left(\partial \ln a_{2} / \partial \ln X_{2}\right)_{T, P}$ for $\mathrm{ACP}$ in this solvent, the molar volume of drug was calculate by means of Fedors method ${ }^{26}$ obtaining a value of $124.4 \mathrm{~cm}^{3} \mathrm{~mol}^{-1}$. From this value and the solubility at $303 \mathrm{~K}$, the value obtained for $\left(\partial \ln a_{2} / \partial \ln X_{2}\right)_{T, P}$ using equation (8) was 0.9994. Since this value is included into the uncertainty obtained in thermodynamic functions of solution, then, the apparent values were used instead of corrected values.

The $\% \varepsilon_{H}$ and $\% \varepsilon_{S}$ values for ACP solvation are also presented in Table 7. These values indicate that during dissolution of ACP in all mixtures studied, the specific solute-solvent interactions (hydrogen bonding, mainly) do not affect the entropic term of free energy with respect to non-specific interactions. With regard to the enthalpic term in all cases the non-specific solute-solvent interactions predominate.

\section{Enthalpy-entropy compensation of solution}

Bustamante et al. ${ }^{8}$ have demonstrated some chemical compensation effects for the solubility of several drug compounds in aqueous cosolvent mixtures. This analysis was used in order to identify the mechanism of the cosolvent action. The making of weighted graphs of $\Delta H_{\text {soln }}^{0}$ as a function of $\Delta G_{\text {soln }}^{0}$ at mean harmonic temperature permits to observe similar mechanisms for the solution process according to tendencies obtained. ${ }^{27}$
For solubility of ACP in EtOH $+\mathrm{W}$, Bustamante and coworkers $^{8}$ obtained a nonlinear trend using seven cosolvent compositions, including the pure solvents. Their data were adjusted to a parabolic regression model obtaining a maximum for $20 \% \mathrm{v} / \mathrm{v}$ of EtOH. From 0 up to $20 \% \mathrm{v} / \mathrm{v}$ of $\mathrm{EtOH}$ a negative slope was obtained while over this EtOH proportion a positive slope was obtained. According to these authors, this fact implies a change from entropy driving to enthalpy driving toward the solution process.

On the other hand, Figure 4 shows the corrected $\Delta H_{\text {soln }}^{0}$ and $\Delta G_{\text {soln }}^{0}$ values for solubility of ACP in PG $+\mathrm{W}$ mixtures obtaining a trend slightly more complex compared with that presented by Bustamante and coworkers $^{8}$ for $\mathrm{EtOH}+\mathrm{W}$ mixtures.

Figure 4 shows fully that this solute-cosolvent system does not present linear $\Delta H_{\mathrm{soln}}^{0}-\Delta G_{\mathrm{soln}}^{0}$ compensation in all compositions studied. Nevertheless, if an interval from $20 \%$ up to $80 \%$ of PG is considered an apparent linear trend is observed with positive slope (without considering $30 \%$ of PG). According to this graph it follows that from pure water up to $10 \%$ of PG and from $20 \%$ up to $70 \%$ of PG the dominant mechanism for solubility is the enthalpy, while from $10 \%$ up to $20 \%$ of PG and from $70 \%$ up to $100 \%$ of PG the dominant mechanism is the entropy.

\section{Conclusions}

From all aspects discussed previously it can be concluded that the solution process of ACP in $\mathrm{PG}+\mathrm{W}$ mixtures is very complex and highly dependent on cosolvent composition. The solvation of this drug is greater for PGrich mixtures especially at $70 \%$ of PG. In a similar way to that found for the solubility of this drug in EtOH $+\mathrm{W}$ mixtures, the solution process in $\mathrm{PG}+\mathrm{W}$ mixtures does 


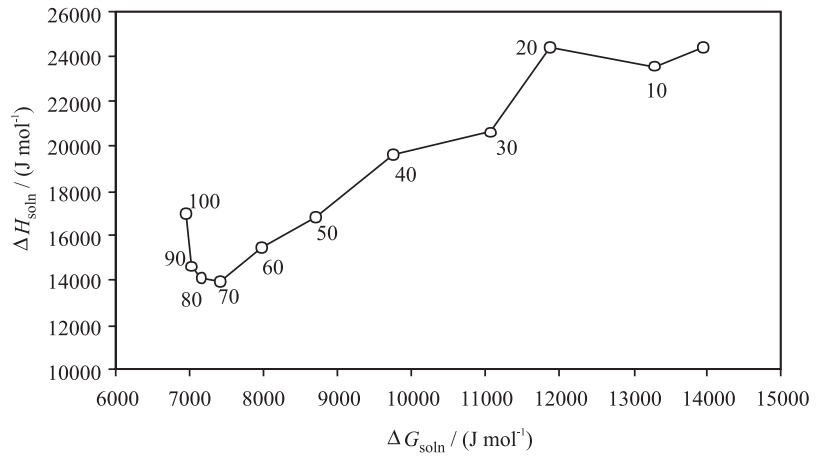

Figure 4. Enthalpy-entropy compensation plot for solubility of ACP in $\mathrm{PG}+\mathrm{W}$ cosolvent mixtures at $303 \mathrm{~K}$.

not follows linear enthalpy-entropy compensation using $\Delta H_{\text {soln }}^{0}$ as a function of $\Delta G_{\text {soln }}^{0}$. This fact at its time is explained as entropy or enthalpy driving for solution process according to the cosolvent mixture composition. Finally, it can be said that all values presented amply the physicochemical information useful in the design of homogeneous liquid pharmaceutical dosage forms.

\section{Acknowledgments}

We thank the Banco de la República and the DIBDINAIN of the Universidad Nacional de Colombia (UNC) for the financial support. Additionally we thank the Department of Pharmacy of UNC for facilitating the equipment and laboratories used.

\section{References}

1. Roberts II, L.J.; Morrow, J.D. In Goodman \& Gilman's. The Pharmacological Basis of Therapeutics, $10^{\text {th }}$ ed.; Hardman, J. G.; Limbird, L. E.; Gilman, A. G., eds.; McGraw-Hill: New York, 2001, ch. 27.

2. Pérez, D. C.; Guevara, C. C.; Cárdenas, C. A.; Pinzón, J. A.; Barbosa H. J.; Martínez, F.; Rev. Col. Cienc. Quím. Farm. 2003, 32, 116.

3. Rubino, J.T. In Encyclopedia of Pharmaceutical Technology; Swarbrick, J.; Boylan, J. C., eds.; Marcel Dekker: New York, 1988, vol. 3; Yalkowsky, S. H.; Solubility and Solubilization in Aqueous Media; American Chemical Society and Oxford University Press: New York, 1999.

4. Jiménez, F.; Martínez, F.; Rev. Col. Cienc. Quím. Farm. 1995, $24,19$.

5. Garzón, L.C.; Martínez, F.; J. Solut. Chem. 2004, 33, 1379.

6. Grant, D. J. W.; Mehdizadeh, M.; Chow, A. H. L.; Fairbrother, J. E.; Int. J. Pharm. 1984, 18, 25.
7. Etman, M. A.; Naggar, V. F.; Int. J. Pharm. 1990, 58, 177.

8. Bustamante, P.; Romero, S.; Reillo, A.; Pharm. Sci. 1995, 1, 505; Bustamante, P.; Romero, S.; Peña, A.; Escalera, B.; Reillo, A.; J. Pharm. Sci. 1998, 87, 1590.

9. Martínez, F.; Rev. Acad. Colomb. Cienc. 2005, 29, 429.

10. US Pharmacopeia, $23^{\text {rd }}$ ed., United States Pharmacopeial Convention: Rockville, MD, 1994.

11. Coronado, Y. P.; Fonseca, J. C.; Luengas, P. E.; Barbosa, H. J.; Martínez, F.; Rev. Col. Cienc. Quím. Farm. 1999, 28, 59.

12. Budavari, S.; O’Neil, M. J.; Smith, A.; Heckelman, P. E.; Obenchain Jr., J. R.; Gallipeau, J. A. R.; D’Arecea, M. A.; The Merck Index, An Encyclopedia of Chemicals, Drugs, and Biologicals, $13^{\text {th }}$ ed.; Merck \& Co., Inc.: Whitehouse Station, NJ, 2001.

13. http://www.euroestar-science.org/conferences/abstrsph7/ wilson.pdf; accessed in October 2004

14. Romero, S.; Reillo, A.; Escalera, B.; Bustamante, P.; Chem. Pharm. Bull. 1996, 44, 1061.

15. Dearden, J. C.; J. Pharm. Sci. 1972, 61, 1661

16. Hildebrand, J. H.; Prausnitz, J. M.; Scott, R. L.; Regular and Related Solutions; Van Nostrand Reinhold: New York, 1970.

17. Krug, R. R.; Hunter, W. G.; Grieger, R. A.; J. Phys. Chem. 1976, 80, 2341

18. Hollenbeck, R. G.; J. Pharm. Sci. 1980, 69, 1241.

19. Manzo, R. H.; Ahumada, A. A.; J. Pharm. Sci. 1990, 79, 1109.

20. Bevington, P. R.; Data Reduction and Error Analysis for the Physical Sciences; McGraw-Hill Book Co.: New York, 1969; Schoemaker, D. P.; Garland, G. W.; Experimentos de Fisicoquímica; Unión Tipográfica Editorial Hispano Americana: México, 1968

21. Martínez F.; Gómez, A.; J. Solut. Chem. 2001, 30, 909.

22. Romero, S.; Bustamante, P.; Escalera, B.; Cirri, M.; Mura, P.; J. Therm. Anal. Calorim. 2004, 77, 541.

23. Martin, A.; Bustamante, P.; Chun, A. H. C.; Physical Pharmacy: Physical Chemical Principles in the Pharmaceutical Sciences, $4^{\text {th }}$ ed.; Lea \& Febiger: Philadelphia, 1993.

24. Perlovich, G. L.; Kurkov, S. V.; Bauer-Brandl, A.; Eur. J. Pharm. Sci. 2003, 19, 423; Perlovich, G. L.; Kurkov, S. V.; Kinchin A. N.; Bauer-Brandl, A.; Eur. J. Pharm. Biopharm. 2004, 57, 411.

25. Baena, Y.; Pinzón, J. A.; Barbosa, H.; Martínez, F.; Phys. Chem. Liq. 2004, 42, 603.

26. Fedors, R. F.; Polym. Eng. Sci. 1974, 14, 147.

27. Leffler, J. E.; Grunwald, E.; Rates and Equilibria of Organic Reactions; Wiley: New York, 1963; Tomlinson, E.; Int. J. Pharm. 1983, 13, 115.

Received: July 13, 2005 Published on the web: December 15, 2005 